\title{
Lysosomal acid lipase: at the crossroads of normal and atherogenic cholesterol metabolism
}

\author{
Joshua A. Dubland and Gordon A. Francis* \\ Department of Medicine, Centre for Heart Lung Innovation, Providence Health Care Research Institute at St. Paul's Hospital, University of British Columbia, \\ Vancouver, BC, Canada
}

\section{Edited by:}

Martin Merkel, Asklepios Clinic St. Georg, Germany

\section{Reviewed by:}

Rhys David Evans, University of Oxford, UK

Vishwajeet Puri, Boston University School of Medicine, USA

*Correspondence:

Gordon A. Francis, St. Paul's Hospital, Room 166 Burrard Bldg., 1081 Burrard St., Vancouver, BC, V6Z 1Y6, Canada

e-mail: gordon.francis@hli.ubc.ca
Unregulated cellular uptake of apolipoprotein B-containing lipoproteins in the arterial intima leads to the formation of foam cells in atherosclerosis. Lysosomal acid lipase (LAL) plays a crucial role in both lipoprotein lipid catabolism and excess lipid accumulation as it is the primary enzyme that hydrolyzes cholesteryl esters derived from both low density lipoprotein (LDL) and modified forms of LDL. Evidence suggests that as atherosclerosis progresses, accumulation of excess free cholesterol in lysosomes leads to impairment of $\mathrm{LAL}$ activity, resulting in accumulation of cholesteryl esters in the lysosome as well as the cytosol in foam cells. Impaired metabolism and release of cholesterol from lysosomes can lead to downstream defects in ATP-binding cassette transporter A1 regulation, needed to offload excess cholesterol from plaque foam cells. This review focuses on the role LAL plays in normal cholesterol metabolism and how the associated changes in its enzymatic activity may ultimately contribute to atherosclerosis progression.

Keywords: Iysosomal acid lipase, atherosclerosis, foam cells, oxidized LDL, lysosomal storage disorders, ABCA1, smooth muscle cells, macrophages

\section{INTRODUCTION}

Atherosclerosis is characterized biochemically by the accumulation of excess cholesterol in the artery wall. This process is initiated by migration of low density lipoproteins (LDL) and other apolipoprotein B (apoB)-containing lipoproteins across an injured artery endothelium, where they are retained through a charge-charge interaction with matrix proteoglycans in the subendothelial space (Tabas et al., 2007). Within this space the trapped lipoproteins are subject to modification including oxidation and aggregation, converting them to ligands for scavenger receptors on intimal macrophages and smooth muscle cells (SMCs). Excessive scavenger receptor-mediated uptake of modified lipoproteins leads to accumulation of cytosolic cholesteryl ester (CE) droplets in these cells, giving them a "foamy" appearance microscopically, hence their name foam cells. There is also evidence that at later stages of atherosclerosis, both free cholesterol (FC) and CE droplets accumulate within the lysosome itself (Jerome, 2006). Lysosomal acid lipase (LAL) plays the central role in hydrolyzing lipoprotein $\mathrm{CE}$ to generate FC, which after leaving the lysosome can be re-esterified in the endoplasmic reticulum to form cytosolic lipid droplets. If excess FC is retained in the lysosome it can inhibit lysosomal activity including that of LAL. The

Abbreviations: ABCA1, ATP-binding cassette transporter A1; ACAT, acylcoenzyme A:cholesterol acyltransferase; aggLDL, aggregated low density lipoprotein; apoA1, apolipoprotein $\mathrm{Al}$; apoB, apolipoprotein $\mathrm{B}$; $\mathrm{CE}$, cholesteryl esters; CESD, cholesteryl ester storage disease; ER, endoplasmic reticulum; FC, free cholesterol; HDL, high density lipoprotein; LAL, lysosomal acid lipase; LDL, low density lipoprotein; LDL-R, low density lipoprotein receptor; $\mathrm{nCEH}$, neutral cholesteryl ester hydrolase; NPC, Niemann Pick type C; oxLDL, oxidized low density lipoprotein; rhLAL, recombinant human lysosomal acid lipase; SMC, smooth muscle cell; TFEB, transcription factor EB; v-ATPase, vacuolar $\mathrm{H}^{+}$-ATPase; VLDL, very low density lipoprotein. physiologic role of LAL may therefore lead to eventual inhibition of LAL activity in the presence of excess atherogenic lipoprotein uptake, contributing further to the progression of atherosclerosis.

\section{LYSOSOMAL ACID LIPASE GENE EXPRESSION AND MUTATION}

LAL is the enzyme with primary responsibility for hydrolysis of $\mathrm{CE}$ and triglycerides in lipoproteins taken up by receptormediated endocytosis. LAL has been called by several names, including lipase $\mathrm{A}$, acid cholesteryl ester hydrolase, acid cholesterol esterase, and acid cholesteryl esterase. LAL is a $46 \mathrm{kDa}$ glycoprotein whose gene LIPA is found on chromosome 10q23.223.3 (Anderson et al., 1993). Human LAL cDNA encodes a 372-amino acid mature protein and a 27-amino acid signaling sequence (Ameis et al., 1994). After undergoing co-translational glycosylation in the endoplasmic reticulum and attachment of mannose-6-phosphate residues in the Golgi apparatus, LAL is targeted to pre-lysosomal compartments (Sando and Henke, 1982; Sheriff et al., 1995). Mutations of LIPA result in complete deficiency of LAL in patients with Wolman disease, which is fatal in the first year of life without LAL replacement, or near-total and non-fatal deficiency known as Cholesteryl Ester Storage Disease (CESD). The most common mutation seen in CESD patients is a splice junction mutation at exon 8 of LIPA, which leads to $\sim 3-5 \%$ of normally spliced LAL protein and LAL activity (Scott et al., 2013; Stitziel et al., 2013). In addition to having fatty liver and spleen enlargement, individuals with CESD have elevated LDL-Cholesterol, low HDL-Cholesterol, and develop premature atherosclerosis, indicating the critical role LAL plays in cellular cholesterol and lipoprotein metabolism (Bernstein et al., 2013; Grabowski et al., 2014). 


\section{TRANSCRIPTIONAL REGULATION}

Several reports have demonstrated an increase in LAL mRNA and protein in the artery wall during the progression of atherosclerosis. Ries et al. (1998) reported that LAL mRNA is increased as human blood monocytes differentiate to macrophages, and that increases in LAL mRNA resulted in higher amounts of LAL enzyme within differentiated macrophages. Therefore, macrophages expressing increased levels of LAL may contribute to the increased LAL activity in the atherosclerotic relative to normal artery wall.

LAL has been shown to be regulated by transcription factors involved in the autophagy pathway. The transcription factor forkhead homeobox type protein O1 (FOXO1) is upregulated in response to nutrient restriction (Sandri, 2012), and has been shown to upregulate LIPA in adipocytes as part of the autophagy response (Lettieri Barbato et al., 2013). It has also been reported that the basic helix-loop-helix (bHLH) transcription factor EB (TFEB), described as a master regulator of autophagy and lysosomal biogenesis, targets the LIPA gene (Sardiello et al., 2009). When cellular nutrient conditions are plentiful TFEB is phosphorylated by mammalian target of Rapamycin complex 1 (mTORC1) and is located in the cytosol on the lysosomal membrane (Settembre et al., 2012). The reader is directed elsewhere for further information regarding upstream signaling mechanisms of autophagy through mTORC1 (He and Klionsky, 2009; Efeyan et al., 2012; Shanware et al., 2013; Sergin and Razani, 2014). Under conditions of starvation and lysosomal stress TFEB is dephosphorylated and translocates to the nucleus for upregulation of genes involved in the lysosomal-autophagic pathway (Settembre et al., 2013). Recently it has been reported that overexpression of TFEB led to a 2.5 -fold increase in LIPA mRNA in mouse peritoneal macrophages (Emanuel et al., 2014). Whether such an upregulation occurs in response to physiologic excursions of TFEB expression is not yet known. Translocation of TFEB to the nucleus and a modest (0.2-fold) upregulation of LIPA also occurred after a $12 \mathrm{~h}$ incubation of peritoneal macrophages with oxidized LDL (oxLDL); the TFEB nuclear localization was reduced at $24 \mathrm{~h}$ of oxLDL incubation, however, indicating this response of LIPA is likely mild and transient (Emanuel et al., 2014). Heltianu et al. (2011) reported no change in LIPA expression in SMCs and a 20\% reduction in LIPA expression in endothelial cells incubated with oxLDL for $24 \mathrm{~h}$. Further studies are required to confirm the importance and cell specificity of TFEBdependent upregulation of LIPA in response to modified forms of LDL and cellular stress induced by excess cell cholesterol.

It has also been demonstrated by Heltianu et al. (2011) that in some cell types LIPA expression increases with liver-X-receptor (LXR) and peroxisome proliferator-activated receptor (PPAR) agonists. LIPA is not known to contain an LXR or PPAR response element in its promoter region. Bowden et al. (2011) demonstrated in CESD fibroblasts that the LXR agonist TO901317 failed to correct LDL-CE hydrolysis and cholesterol efflux to apolipoprotein A1 (apoA1), indicating the residual expression of LAL in CESD cells was not increased by the LXR agonist. LIPA response to LXR and PPAR $\gamma$ agonists may be cell type specific and involve stimulation of the autophagy pathway. LXR is not a known target of TFEB, whereas peroxisome proliferator-activated receptor gamma coactivator 1 -alpha (PGC-1 $\alpha)$, which interacts with PPAR $\gamma$, is a transcriptional target of TFEB (Sardiello et al., 2009).

Our understanding of the transcriptional regulation of LIPA in the artery wall during the progression of atherosclerosis is far from complete. Initially it was hypothesized by De Duve (1974) that a deficiency in LAL was the cause of intracellular accumulations of lipids in atherosclerosis. Supporting this hypothesis was the observation of lipid-engorged lysosomes in post-mortem liver tissue samples from Wolman disease patients having complete absence of LAL (Patrick and Lake, 1969; Lake and Patrick, 1970) and premature atherosclerosis seen in the neartotal LAL deficiency CESD (Sloan and Fredrickson, 1972). Several groups subsequently reported that LAL activity was increased in atherosclerotic tissue (Brecher et al., 1977; Takano, 1978; Subbiah, 1979). Haley et al. (1980) indicated a 2-fold increase in LAL activity in lipid-laden lysosomes isolated by density centrifugation from atherosclerotic tissue homogenates. Davis et al. (1985) reported that increased LAL activity in human aortic lesions at various stages of disease correlated with increased macrophage infiltration. These studies do not support the LAL deficiency hypothesis of atherosclerosis. It is not yet clear whether increased LAL in atherosclerotic tissue is a result of upregulation of LAL within cells or a higher number of LAL-expressing cells present in the lesion, but potentially both.

\section{REGULATORY ROLE OF LYSOSOMALLY-DERIVED CHOLESTEROL}

Cholesterol is a component of all cell membranes, and is the precursor for oxysterol, steroid hormone, bile acid, and vitamin D synthesis. FC released by lysosomes from lipoprotein and membrane turnover is an important substrate pool for these metabolites. In addition the lysosomally-derived cholesterol pool has multiple regulatory roles through inhibition of sterol regulatory element binding protein (SREBP) cleavage activating protein (SCAP) in the endoplasmic reticulum, and downregulation of SREBP-dependent new cholesterol synthesis and LDL receptor expression by the cell (Brown and Goldstein, 1997). In this way cholesterol released from lysosomes is a critical regulator of overall cell cholesterol homeostasis. When flux of FC from lysosomes is high, oxysterol levels including 27-hydroxycholesterol are increased and bind to the nuclear receptor liver $\mathrm{X}$ receptor (LXR), which activates transcription of several genes involved in the removal of cholesterol from cells and other steps in reverse cholesterol transport (Venkateswaran et al., 2000). One of these genes encodes the ATP-binding cassette transporter A1 (ABCA1), a plasma membrane protein that promotes cholesterol efflux to apoA1, the rate-limiting step in the formation of high density lipoproteins (HDL) (Oram and Heinecke, 2005). The importance of lysosomally-derived cholesterol in, and the inability of increased de novo synthesis of cholesterol (Goldstein et al., 1975; Liscum and Faust, 1987) to correct, ABCA1 expression has been demonstrated in the lysosomal cholesterol storage disorders Niemann Pick Disease type C (NPC) and CESD (Choi et al., 2003; Bowden et al., 2011). In both cases the reduced flux of FC out of lysosomes leads to reduced 27-hydroxycholesterol production and reduced ABCA1 expression, the likely cause of low plasma HDL-C in both these disorders (Garver et al., 2010; 
Bernstein et al., 2013). Delivery of exogenous oxysterols to NPC fibroblasts (Boadu et al., 2006) and recombinant human LAL to CESD fibroblasts (Bowden et al., 2011) were both able to correct ABCA1 expression and cholesterol efflux to apoA1. This indicates that the rate of release of FC from the lysosome after both LALdependent CE hydrolysis and the action of Niemann Pick type C1 (NPC1) protein in the lysosomal membrane is a critical determinant of cholesterol-dependent gene regulation. As hydrolysis of CE derived from both LDL and modified LDL in the lysosome is also likely to be a key regulator of ABCA1 expression in cells in atherosclerotic lesions, a defect in LAL activity could result in impaired ABCA1-dependent cholesterol efflux from macrophage and SMC foam cells.

\section{LIPOPROTEIN UPTAKE AND LIPID ACCUMULATION}

Uptake of LDL through cell surface LDL-receptors is tightly regulated and therefore insufficient to explain intimal foam cell formation (Goldstein and Brown, 1977, 2009). Within the artery wall LDL and other apoB-containing particles become oxidized, aggregated, or enzymatically-modified (Aviram, 1993; Bhakdi et al., 1995; Hoff and Hoppe, 1995; Chisolm and Steinberg, 2000; Torzewski and Lackner, 2006) (Figure 1). These altered forms of LDL are no longer recognized by the LDL receptor but are recognized and taken up by scavenger receptors expressed on macrophages and SMCs, a cellular process that is not feedback regulated and can lead to massive accumulation of cholesterol in these cells (Brown et al., 1979; Brown and Goldstein, 1983; Moore and Freeman, 2006). Scavenger receptors as well as the LDL receptor utilize the endocytic pathway for delivery of cargo to lysosomes. Lipoprotein cholesterol is primarily in the form of $\mathrm{CE}$, which is hydrolyzed within lysosomes by LAL, the only lysosomal lipase known to perform this function (Brown et al., 1975; Goldstein and Brown, 1977; Aviram, 1993; Dhaliwal and Steinbrecher, 2000; Yancey and Jerome, 2001; Griffin et al., 2005). LAL in the lysosome is most catalytically active at $\mathrm{pH} 3.5-$ 4.5 (Takano et al., 1974; Haley et al., 1980). The FC released from lipoprotein $\mathrm{CE}$ is transported out of the lysosome by the concerted actions of the Niemann-Pick Type C2 (NPC2) and NPC1 lysosomal proteins, with one fate of the FC then being re-esterification in the endoplasmic reticulum by acyl-coenzyme

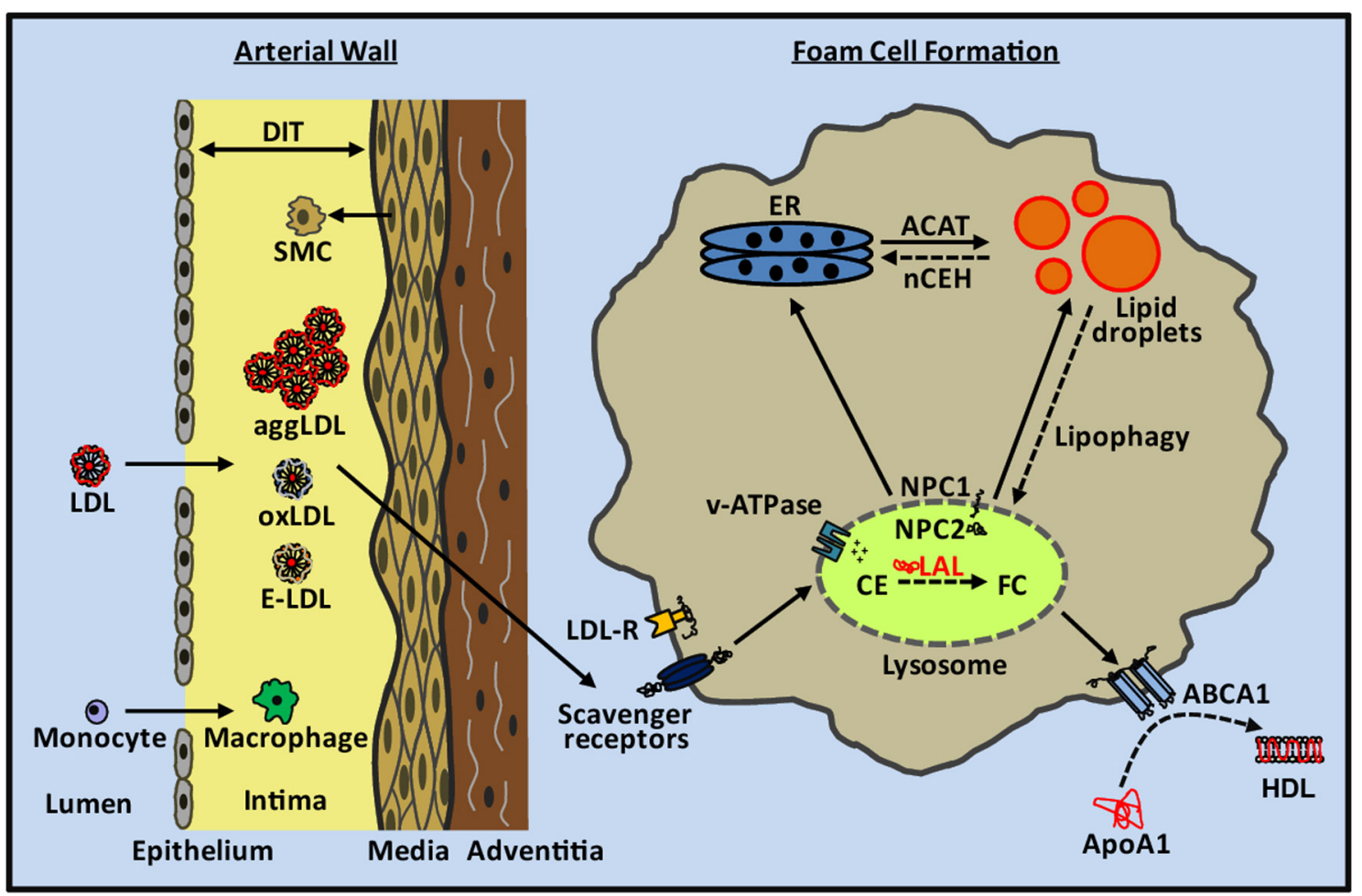

FIGURE 1 | Cholesterol metabolism in atherosclerotic lesion foam cells. LDL and other apoB-containing lipoproteins pass through the damaged endothelium and undergo aggregation, oxidation, and enzymatic modification within the intima of the arterial wall. SMCs from the media migrate to the intima and contribute to diffuse intimal thickening (DIT). Monocytes enter through the damaged endothelium and differentiate into macrophages. SMCs and macrophages take up aggLDL, oxLDL, and enzymatically-modified LDL (E-LDL) through scavenger receptors in an unregulated manner, and deliver their cargo to the lysosome through the endocytic pathway. Within the lysosome, lipoprotein cholesteryl esters (CE) are hydrolyzed by LAL to generate free cholesterol (FC). The $\mathrm{pH}$ of the lysosome is acidified by the proton pumping action of v-ATPases. FC leaves the lysosome through the concerted action of NPC2 and NPC1 proteins and is transported within the cell including to the endoplasmic reticulum (ER) where it is re-esterified by ACAT and accumulates as lipid droplets within the cytosol. CE in lipid droplets can be hydrolyzed by $\mathrm{nCEH}$ and used for cellular functions or removed from the cell along with phospholipids by the actions of ABCA1 to create new HDL particles. CE in lipid droplets can also be transported back to the lysosome through the lipophagy pathway for hydrolysis by $L A L$ and cellular removal of FC via ABCA1. Early atherosclerotic lesion foam cell lipid droplets are primarily cytosolic whereas later stage lesion foam cells contain a mixture of ACAT-derived lipid droplets and lysosomal lipid droplets. 
A:cholesterol acyltransferase (ACAT) (Kwon et al., 2009). Reesterification is a protective mechanism to prevent the toxicity of excess FC in membranes (Tabas, 2002), particularly in the endoplasmic reticulum, with the reformed CE then stored in the cytoplasm as benign lipid droplets (Brown and Goldstein, 1983). $\mathrm{CE}$ in foam cell cytosolic lipid droplets can be transported back to lysosomes through the autophagic process termed "lipophagy" (Singh et al., 2009); cholesterol derived from this process appears to form a large part of the substrate pool of ABCA1 for efflux from cells (Ouimet et al., 2011).

During early stages of atherosclerosis foam cells appear as visible fatty streaks in the intima of the artery wall (Haust, 1971). In addition to the presence of macrophage derived foam cells, SMCs present in the intima beginning in the pre-atherosclerotic diffuse intimal thickening stage also take up modified forms of LDL via scavenger receptors to become smooth muscle derived foam cells (Li et al., 1995; Doran et al., 2008). It has been previously thought macrophages were the major contributors to foam cells in the intima, however recent studies from our lab suggest SMCs are the source of more than $50 \%$ of the total foam cell population in human coronary artery atherosclerotic lesions (Allahverdian et al., 2014).

\section{OVERACCUMULATION OF CHOLESTEROL IN LYSOSOMES}

Retention of LDL and other apoB-containing lipoproteins in the arterial intima by matrix proteoglycans, as a result of chargecharge interactions (Williams and Tabas, 1995, 2005), means these lipoproteins are susceptible to modification to more atherogenic forms. This modification, either by enzymes, oxidants, or through aggregation converts these lipoproteins to ligands for scavenger receptors and allows for the formation of cholesteroloverloaded foam cells (Hoff and Hoppe, 1995; Torzewski and Lackner, 2006). Within the intima LDL has been demonstrated to undergo both extracellular and intracellular modifications (Aviram, 1993; Bhakdi et al., 1995; Hoff and Hoppe, 1995; Torzewski et al., 1998; Chisolm and Steinberg, 2000; Steinberg and Witztum, 2002; Stocker and Keaney, 2004; Wen and Leake, 2007). LAL and lysosomal enzymes have also been implicated in the modification of LDL, and, conversely, modified forms of LDL have been shown to affect lysosomal function and lead to changes in LAL activity.

\section{EXTRACELLULAR MODIFICATION OF LDL BY LAL}

LAL is present within the extracellular space of atherosclerotic intima (Hakala et al., 2003), and there are indications that LAL may actively participate in the modification of retained LDL. Secretion of lysosomal enzymes by macrophages is known to occur without stimuli, and increase under inflammatory conditions (Schnyder and Baggiolini, 1978). Catalytic activity of LAL would require conditions of at least localized reduced $\mathrm{pH}$ in the extracellular space. Naghavi et al. (2002) reported that $\mathrm{pH}$ heterogeneity exists within atherosclerotic lesions with increased acidity in lipid-rich, macrophage-containing areas compared to calcified areas of human and rabbit atherosclerotic plaque. Microenvironments with much lower $\mathrm{pH}$ supportive of LAL activity may exist within lesions, as macrophages can acidify their pericellular space through the action of proton pumps (Tapper and
Sundler, 1992) and by secreting lactic acid (Newsholme et al., 1987). Buton et al. (1999) reported that CE present in matrixretained aggregated LDL (aggLDL) may be hydrolyzed by LAL during extensive cell-surface contact with cultured macrophages. Fluorescence microscopy was utilized to indicate that the matrixretained aggLDL was present on the cell surface during CE hydrolysis; definitive proof that the observed CE hydrolysis is extracellular is still needed. Thus, LAL might be present in a catalytically active form in the pericellular space of macrophages within lesions, which could contribute to extracellular CE hydrolysis and atherogenic modification of apoB containing particles. In support of CE hydrolysis of LDL increasing the atherogenicity of LDL, human macrophages have been shown to take up LDL modified by hydrolysis with neutral cholesteryl ester hydrolase $(\mathrm{nCEH})$ at a rate exceeding that of oxLDL or acLDL (Bhakdi et al., 1995). Further evidence is required to know whether extracellular hydrolysis of LDL CE by LAL increases uptake of the modified LDL by scavenger receptors.

\section{OXIDATIVE MODIFICATION OF LDL}

Oxidation of LDL is proposed to contribute to foam cell formation by virtue of oxLDL being a ligand for scavenger receptors. The presence of oxLDL within atherosclerotic lesions has been demonstrated by immunostaining using antibodies generated against oxLDL epitopes (Mehrabi et al., 2000). Within the artery wall, oxidation of LDL may occur by a number of concurrent mechanisms involving enzymes (e.g., myeloperoxidase, NADPH oxidase, lipoxygenase, and xanthine oxidase), peroxynitrite-generators, superoxide, low levels of metal ions, and thiols (Gaut and Heinecke, 2001; Parthasarathy et al., 2010; Yoshida and Kisugi, 2010), and is thought to occur mainly within the interstitial fluid of atherosclerotic lesions.

The presence of oxidized sterols within human atherosclerotic tissue and lesion LDL has been reported. Steinbrecher and Lougheed (1992) found 7-ketocholesterol, 7-hydroxycholesterol, and 5,6-epoxycholesterol in LDL isolated from atherosclerotic but not healthy aortas. Significant accumulations of oxysterols are present in atherosclerotic lesions (Brown and Jessup, 1999). Quantitative comparison of in vitro studies conducted using oxLDL is difficult due to the variety of methods by which LDL is oxidized and the degree of oxidation induced (Yancey and Jerome, 2001; Orso et al., 2011). Oxidative modification of apoB by oxidized lipids reduces recognition of LDL by the LDL receptor and increases its affinity for scavenger receptors, making oxLDL a potent promoter of foam cell formation in vitro (Jessup and Kritharides, 2000). In vitro studies show a significant fraction of the sterols present in oxLDL are retained within the lysosome and that oxidized CE are resistant to hydrolysis by LAL (Yancey and Jerome, 1998; Brown et al., 2000). Of note, LDL isolated from human atherosclerotic plaques was found to be largely aggregated and only mildly oxidized (Steinbrecher and Lougheed, 1992; Niu et al., 1999).

\section{AGGREGATION OF LDL}

Isolated aortic LDL fractions from human lesions are potent inducers of macrophage $\mathrm{CE}$ accumulation relative to normal aortic LDL fractions and plasma LDL 
(Goldstein et al., 1981; Hoff and Morton, 1985). Steinbrecher and Lougheed (1992) demonstrated that this affect was due primarily to aggLDL isolated from human atheromas. The presence of aggLDL in the extracellular space of human atherosclerotic tissue was also reported using electron microscopy (Guyton and Klemp, 1993). In vivo, aggregation of LDL may be a result of a variety of stimuli including oxidation, extracellular matrix interactions, phospholipase $\mathrm{A}_{2}$ and $\mathrm{C}$, sphingomyelinase, and glycosylation (Falcone and Salisbury, 1988; Suits et al., 1989; Hoff et al., 1990; Xu and Tabas, 1991; Tertov et al., 1992; Maor and Aviram, 1999; $\mathrm{Xu}$ and Lin, 2001; Kruth, 2002). As oxidation is known to cause aggregation of LDL it may be difficult to separate the relative contributions of oxLDL and aggLDL to foam cell (Figure 2) formation in the atherosclerotic intima.

\section{EFFECTS OF EXCESS MODIFIED LDL UPTAKE ON LYSOSOMAL HYDROLYTIC FUNCTION}

Previous studies have reported variable effects of different forms of modified LDL on accumulation of cholesterol either in the cytosol alone or also in lysosomes, with oxLDL and aggLDL causing accumulation of cholesterol in lysosomes, while enzymatically-modified and acetylated LDL cause mainly cytosolic accumulations (Yancey and Jerome, 2001; Griffin et al., 2005; Orso et al., 2011). Treatment of THP-1 macrophages in culture with mildly oxLDL or aggLDL shows similar trends in loss of lysosomal hydrolysis (Yancey and Jerome, 2001; Griffin et al., 2005). Initially CE hydrolysis is not inhibited but lysosomal sequestration of FC occurs. After prolonged exposure to mildly oxLDL or aggLDL ( $48 \mathrm{~h}$ or more) increasing inhibition of CE hydrolysis occurs and lysosomal accumulation switches to mainly CE (Yancey and Jerome, 2001; Griffin et al., 2005).

Some variability between species has been observed (Griffin et al., 2005). Yancey and Jerome (1998) reported that THP1 human macrophages and pigeon macrophages store FC and CE derived from mildly oxLDL within lysosomal compartments, whereas mouse macrophages stored most of the cholesterol in cytosolic lipid droplets. Interestingly, acLDL was efficiently

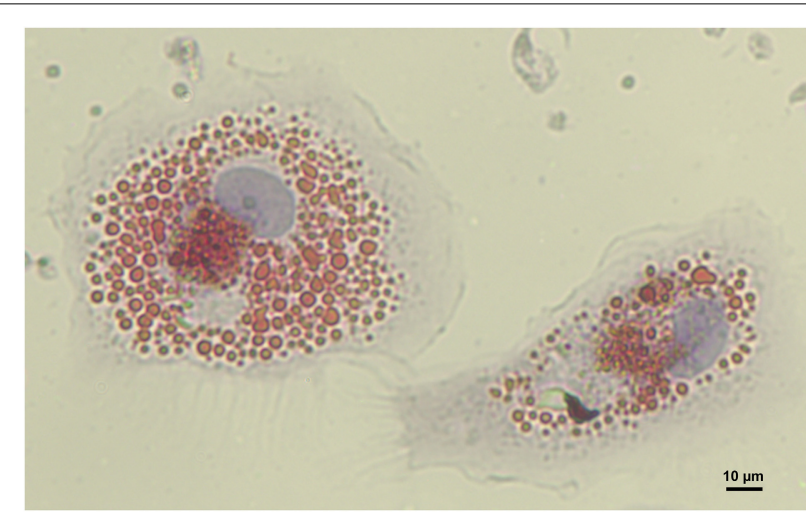

FIGURE 2 | Human monocyte derived macrophage foam cells. Foam cells were generated by incubation of macrophages with $100 \mu \mathrm{g} / \mathrm{mL}$ aggregated LDL for $48 \mathrm{~h}$. Cells were then fixed and intracellular lipids stained using Oil Red O (image provided by Dubland, J. A.). hydrolyzed in macrophages regardless of the species and led to cytosolic lipid droplet accumulation (Yancey and Jerome, 1998). Maor and Aviram (1994) reported that the addition of oxysterols isolated from oxLDL to medium when loading J-774 mouse macrophages with acLDL led to significant lysosomal FC accumulations.

Cox et al. (2007) have reported a general loss of lysosomal function including reduction in LAL-dependent CE hydrolysis over time following incubation of THP-1 human macrophages with mildly oxLDL or aggLDL. The similar effects using unoxidized aggLDL and oxLDL suggest this inhibition of lysosomal function is not specific to the effects of oxidized lipids. Increasing levels of lysosomal membrane FC during lipid loading were shown to inhibit lysosomal acidification (Cox et al., 2007). It was demonstrated using fluorescence quenching studies that excess FC in the lysosomal membrane leads to loss of acidity as a result of inhibition of vacuolar $\mathrm{H}^{+}$-ATPase (v-ATPase) proton pumping activity in the lysosomal membrane, without a change in the amount of v-ATPase protein. The resultant increase in $\mathrm{pH}$ within the lysosome corresponded with a time-dependent inhibition of $\mathrm{CE}$ hydrolysis and accumulation of apoB, indicating a general decline in lysosomal hydrolytic activity. After 7 days of incubation with mildly oxLDL or aggLDL, the majority of lysosomal vesicles within THP-1 macrophages had $\mathrm{pH}>4$.8. Vacuolar ATPase activity could be partially recovered if isolated lysosomes were treated with cyclodextrins in order to remove membrane cholesterol. As LAL is only active at acidic $\mathrm{pH}$, with maximal activity $\sim \mathrm{pH} 4$ and very little activity above $\mathrm{pH} 4.5$ (Burton et al., 1980; Haley et al., 1980), this loss of v-ATPase activity in response to cholesterol loading of the lysosomal membrane may be the main cause of loss of hydrolytic activity of LAL, and hence lead to lysosomal lipid droplet accumulations.

In contrast to oxLDL and aggLDL, incubation of THP-1 macrophages with acLDL, an experimental rather than physiologic form of modified LDL, did not result in an increase in lysosomal membrane FC or an increase in lysosomal $\mathrm{pH}$ (Cox et al., 2007). The reasons for the differential effects of acLDL and oxLDL or aggLDL on sequestration of FC in lysosomal membranes following hydrolysis by LAL are unknown. In order to investigate if the observed neutralization of lysosomal $\mathrm{pH}$ and inactivation of LAL following oxLDL uptake could be reversed by acLDL, THP-1 macrophages were incubated for 3 days in the presence of oxLDL to accumulate lysosomal CE and then chase incubated with acLDL for an additional 3 days (Jerome et al., 2008). Hydrolysis of CE in the chase acLDL incubation was inhibited and the loss of acidic $\mathrm{pH}$ from the initial loading with oxLDL was maintained, indicating lysosomal dysfunction was not readily reversible. Similar results were found in human monocyte derived macrophages. This data indicates that inhibition of LAL activity is the result of a long-lived alteration in lysosomal function under excess lipid loading.

Emanuel et al. (2014) also found a loss of lysosomal acidity occurred in mouse peritoneal macrophages at $72 \mathrm{~h}$ of oxLDL treatment and in isolated macrophages from atherosclerotic aortic tissue of $\mathrm{ApoE}^{-/-}$mice. This group also reported that overexpression of TFEB in mouse peritoneal macrophages was able to preserve lysosomal acidity, by mechanisms that are not yet clear. 
An interesting study by Ullery-Ricewick et al. (2009) demonstrated that in THP-1 human macrophages lysosomal CE accumulations from aggLDL could be reduced by $50 \%$ by chase incubation with triglyceride (TG)-rich lipid dispersions or VLDL. It was shown that TG treatment reestablished acidic $\mathrm{pH}$ by restoring proton pumping by $\mathrm{v}$-ATPases in the lysosomal membrane (Ullery-Ricewick et al., 2009). TGs also increased LAL activity, with no change in LAL expression. The exact mechanism by which TG-containing particles restore lysosomal function in foam cells remains to be determined; however, it was demonstrated to not be a result of competitive uptake of TG-rich vs. CE-rich particles (Ullery-Ricewick et al., 2009). This is further evidence that inhibition of $\mathrm{v}$-ATPase proton pumping in the lysosomal membrane leads to loss of LAL activity and lysosomal CE accumulations, but may be reversible under some conditions. Further investigation is needed to evaluate the role of TGs in lysosomes of arterial wall foam cells, including the signaling role of TG-derived fatty acids on the LXR and PPAR metabolic pathways.

An alternative or additional reason for the increase in lysosomal pH is that excess membrane FC and oxidized FC can cause lysosomal leakiness, leading to a loss of the proton gradient. $\mathrm{Li}$ et al. (1998) reported that incubation of J-744 macrophages with oxLDL resulted in leakage of lysosomal enzymes into the cytosol. Yuan et al. (2000) found that a mixture of cholesterol oxidation products found in oxLDL were also able to induce damage to lysosomes and leakage of lysosomal contents into the cytosol, and eventual macrophage cell death. Although leakiness was not implicated in the studies by Cox et al. (2007) using mildly oxLDL or aggLDL, as apoptosis was not observed, it may be a long term contributing factor in vivo. The presence of free cholesterol crystals has been reported in J774 macrophage foam cells (Tangirala et al. (1994), and treatment of mouse peritoneal macrophages with free cholesterol was shown to induce lysosomal membrane leakiness (Emanuel et al. (2014). An increase in lysosomal pH has also been shown to increase extracellular excretion of lysosomal enzymes (Tapper and Sundler, 1990), which may contribute to the extracellular LAL observed in atherosclerotic lesions (Hakala et al., 2003). Overall it appears that increases in lysosomal FC induce both defects in lysosome acidification and leakiness of the lysosomal membrane.

Oxidation of apoB-100 has been reported to increase its resistance to degradation by cathepsin $\mathrm{D}$ in mouse peritoneal macrophages and its accumulation in lysosomal compartments (Lougheed et al., 1991; Jessup et al., 1992; Roma et al., 1992; Hoppe et al., 1994; Mander et al., 1994). Decreased apoB-100 protein degradation may also limit LAL mediated hydrolysis of the CE lipid core of oxLDL. Oxidized phospholipids in oxLDL can inhibit cathepsin $\mathrm{D}$, which may explain the reduced ability to degrade apoB (O'neil et al., 2003). Oxidized phosphatidylcholineapoB complexes have been found in human atherosclerotic lesions and also in lysosomes of cultured mouse macrophages incubated with oxLDL (Itabe et al., 2000). Brown et al. (2000) found that oxidized CE from heavily oxidized LDL loading are resistant to hydrolysis by LAL and accumulate in lysosomal compartments. Therefore, oxidative modifications to apoB containing particles may lead to impaired lysosomal clearance for reasons additional to those induced by non-oxidized aggLDL.

\section{LYSOSOMAL CHOLESTEROL ACCUMULATION IN ATHEROSCLEROSIS}

In the absence of genetic deficiency in LAL, in vivo studies including electron microscopy have indicated that, in addition to storage of $\mathrm{CE}$ droplets in the cytoplasm, there are substantial accumulations of FC and CE within the lysosomes of foam cells (Jerome and Yancey, 2003). This phenomenon has been previously reported for both human (Coltoff-Schiller et al., 1976) and animal (Peters et al., 1972; Shio et al., 1974, 1979; Goldfischer et al., 1975; Fowler et al., 1980; Jerome and Lewis, 1985) atherosclerosis. It has been indicated that as atherosclerosis progresses there is initially an increasing amount of FC retained in lysosomes, and at later disease stages also retention of lyososomal CE (Jerome, 2006). A possible conclusion that can be drawn from this is that there is a general loss of lysosomal function due to cholesterol overload following unregulated cellular uptake of modified forms of LDL within artery wall cells. As LAL hydrolyzes lipoprotein $\mathrm{CE}$, the loss of LAL function due to excess FC within the lysosome contributes to the formation of foam cells and the altered distribution of lipid stores within these cells. Therefore, atherosclerosis has been proposed as a type of lysosomal storage disorder (Miller and Kothari, 1969; Peters et al., 1972; Peters and De Duve, 1974; Shio et al., 1974; Coltoff-Schiller et al., 1976; Jerome and Lewis, 1985).

As indicated above, the reason for the loss of lysosomal hydrolytic function may not be a result of deficiency in LAL expression as atherosclerosis progresses but rather a decrease in the catalytic activity of LAL as a result of excess lysosomal cholesterol accumulation from modified forms of LDL (Figure 3). LAL remains catalytically active initially but over time FC in the lysosomal membrane increases and inhibits the proton pumping ability of the v-ATPases. As a result, the $\mathrm{pH}$ of the lysosome increases and renders LAL catalytically inactivate. Lysosomal CE accumulation then occurs in addition to cytosolic accumulation in later stage atherosclerotic lesions.

Previous studies in atherosclerotic tissue have indicated that LAL activity is increased relative to non-atherosclerotic arteries (Brecher et al., 1977; Takano, 1978; Subbiah, 1979; Haley et al., 1980; Davis et al., 1985). The analytical procedures for those studies, however, involved ex vivo acidic $\mathrm{pH}$ adjustment and therefore reflects the total amount of potentially active LAL present, but not what may be actually active in vivo within intact cells under the influence of excess lipids and altered lysosomal $\mathrm{pH}$. As activity is also reflective of protein amount, these studies may indicate that LAL expression increases to deal with the increased cellular influx of apoB containing particles within the artery wall. It can be proposed that LAL activity and protein amount in arterial cells increases with lipid challenge up to a certain point, either from increased LAL expression per cell or an increase in total LAL-expressing cells, after which the lysosome is overwhelmed with lipids and the activity of LAL decreases due to increased $\mathrm{pH}$ caused by excess lysosomal membrane cholesterol and leakiness.

\section{INDICATIONS OF A LYSOSOMAL CHOLESTEROL TRAFFICKING DEFECT}

The question then arises what is responsible for the elevation of lysosomal FC in response to the excess lipoprotein load in 


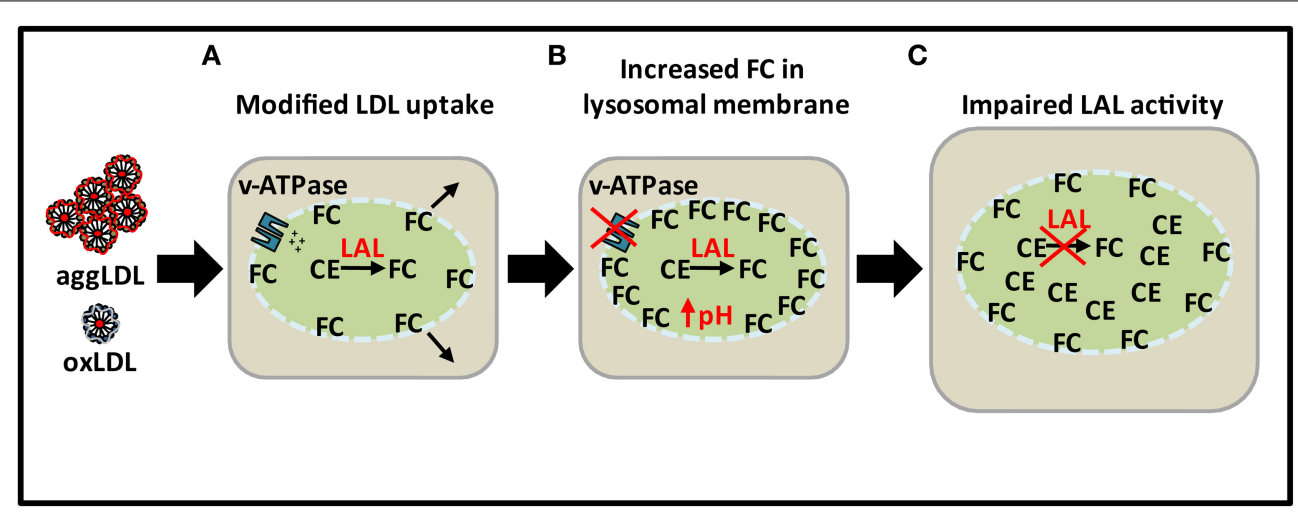

FIGURE 3 | Loss of lysosomal function with excess lipid loading. (A) CE from excess modified $L D L$ is hydrolyzed by $L A L$ to produce $F C$. (B) Sequestration of $\mathrm{FC}$ in lysosomal membrane leading to increase in $\mathrm{pH}$ as a result of inhibition of ATPase proton pumping ability. (C) Impairment of $\mathrm{LAL}$ activity as a result of increased $\mathrm{pH}$ leading to $\mathrm{CE}$ accumulation in lysosomes. the intima. As NPC1 and NPC2 facilitate the release of FC from the lysosome, investigation of the expression and activity of these proteins may provide useful insight in this area. Previous studies in fibroblasts have suggested that retention of cholesterol within lysosomal compartments may serve to protect cells from endoplasmic reticulum (ER) stress caused by an excess of FC in the ER membrane. Garver et al. (2008) and Jelinek et al. (2009) found that loading normal human fibroblasts with LDL results in reduced SREBP-dependent expression of NPC1 and NPC2. Jelinek et al. (2012) reported that in a mouse model of diet induced obesity, dietary fatty acids but not cholesterol induced down regulation of NPC1 in both hepatic cells and peritoneal fibroblasts via feedback inhibition of the SREBP pathway. In THP-1 macrophages it has been reported that oxLDL treatment for 3 days leads to a buildup of NPC1 protein in the Golgi apparatus (Jerome et al., 2002). Differential responses to cholesterol-dependent manipulations of NPC1 and NPC2 expression have been indicated in the literature. Rigamonti et al. (2005) demonstrated that expression of NPC1 and NPC2 increased in the presence of LXR agonists in human but not mouse macrophages. It has also been demonstrated that treatment of human macrophages with oxLDL leads to increases in NPC1 and NPC2 expression via PPAR $\alpha$ - and mitogen-activated protein kinase (MAPK)-dependent pathways (Chinetti-Gbaguidi et al., 2005; Yu et al., 2012). These results indicate that the expression of NPC1 and NPC2 with lipid overload varies between cell types and species. Further investigation is needed to elucidate the reason for FC overload in the lysosomes of atherosclerotic foam cells.

As the rate of release of $\mathrm{FC}$ from the lysosome is a regulator of ABCA1 expression, lysosomal dysfunction in atherosclerosis may also lead to decreased expression of ABCA1 in artery wall cells. Choi et al. (2009) have reported that model human intimal SMCs as well as human coronary artery intimal SMCs express lower levels of ABCA1 than medial SMCs. More recently, Allahverdian et al. (2014) reported that intimal SMCs but not myeloid lineage cells express lower levels of ABCA1 in late vs. early stage human atherosclerotic lesions. Further studies are required to determine whether decreased LAL catalytic activity as a result of lysosomal dysfunction is responsible for this defect in ABCA1 expression, and hence further contributing to the overaccumulation of cholesterol in intimal SMC foam cells.

\section{LAL AUGMENTATION IN ATHEROSCLEROSIS}

Recombinant human LAL (rhLAL) is currently in phase 3 clinical trials to treat LAL deficiency in Wolman disease and CESD. This treatment is potentially life-saving in Wolman disease. Phase 2 clinical trials in patients with CESD using rhLAL demonstrated safety and improvements in serum lipid profiles (Balwani et al., 2013). Long-term follow up will be needed in CESD patients to determine outcomes in terms of cardiovascular events. Several studies in mice have indicated that rhLAL may be beneficial in reversing atherosclerosis. Studies by Du et al. (2001) and Sun et al. (2014) demonstrated that injection of rhLAL into $\mathrm{LAL}^{-/-}$ mice was able to reverse the pathogenic storage of lipids in multiple tissues. Du et al. (2004) also showed that administration of repeat doses of rhLAL to LDL-receptor-deficient mice fed a high fat/cholesterol diet resulted in complete regression of early stage lesions in coronary and aortic tissue and a significant reduction in late stage lesions.

Although rhLAL treatment seems to be a viable therapeutic strategy for premature atherosclerosis in CESD patients, it is unclear what the effects would be of rhLAL treatment in patients having atherosclerosis unrelated to a deficiency in LAL. The lysosomal acid lipase A (LIPA) gene has been identified as a susceptibility gene for coronary artery disease by several genome-wide association studies (Consortium, 2011; Coronary Artery Disease Genetics, 2011; Wild et al., 2011). For the reasons outlined here, increasing the activity of LAL beyond the normal cellular response may not be an effective strategy. As scavenger receptor mediated uptake of modified forms of LDL in both macrophages and SMCs occurs in atherosclerotic lesions, it is conceivable that rhLAL treatment might increase lysosomal membrane FC in these cells by increasing the rate of lipoprotein CE hydrolysis, and thereby exacerbate lysosomal dysfunction. Reducing the level of atherogenic lipoproteins in plasma and their initial influx into the artery wall, therefore, remains of paramount importance. 


\section{CONCLUSION}

The role of LAL in the progression of atherosclerosis is complex. Modified forms of LDL such as oxLDL and aggLDL lead to lysosomal accumulations of first FC and later $\mathrm{CE}$, indicating an acquired loss of LAL hydrolytic activity. In agreement with this observation, tissue studies have indicated increased lysosomal lipid accumulations in addition to cytosolic lipid droplets at later stages of atherosclerosis. Activity assays of atherosclerotic tissue homogenates have indicated an increase in LAL and also other lysosomal enzymes. As these studies are conducted ex vivo using acidic $\mathrm{pH}$ adjustment, they are representative of potentially functional LAL present in vivo but not necessarily actual LAL activity. Therefore, although the amount of artery wall LAL may increase in response to increased cellular influx of apoB-100 containing lipoproteins, the hydrolytic activity of LAL may decrease over time as lysosomal function is impaired. Sequestration of cholesterol in the lysosomal membrane has been implicated as a cause of lysosomal dysfunction, specifically through the inhibition of $\mathrm{v}$-ATPase proton pumping. Increasing lysosomal $\mathrm{pH}$ reduces the activity of LAL. The result of this is a time dependent switch of lysosomal accumulation of FC to CE. Early stage atherosclerosis may involve normal and perhaps increased LAL activity leading to cytosolic lipid droplet accumulation, whereas later stages of atherosclerosis may have an acquired dysfunction in LAL hydrolytic activity leading to lysosomal lipid sequestration. Therefore, later stages of atherosclerosis, where LAL function is inhibited, may be considered to be morphologically similar to Wolman disease and CESD, albeit for an entirely different reason.

Outside of alleviating premature onset of atherosclerosis associated with genetic deficiency in LAL, it is hard to predict whether augmentation of LAL is a good therapeutic strategy. There are indications that selective upregulation of the autophagiclysosomal pathway may be able to recover lysosomal function and LAL hydrolysis. It is unclear, however, whether induction of this pathway beyond normal response is a viable in vivo strategy. Further research is necessary to know whether manipulation of arterial cell LAL activity is likely to alleviate or aggravate the consequences of cholesterol accumulation in the artery wall.

\section{ACKNOWLEDGMENT}

This work was supported by the Canadian Institutes of Health Research (CIHR) grant MOP 79532.

\section{REFERENCES}

Allahverdian, S., Chehroudi, A. C., Mcmanus, B. M., Abraham, T., and Francis, G. A. (2014). Contribution of intimal smooth muscle cells to cholesterol accumulation and macrophage-like cells in human atherosclerosis. Circulation 129, 1551-1559. doi: 10.1161/CIRCULATIONAHA.113.005015

Ameis, D., Merkel, M., Eckerskorn, C., and Greten, H. (1994). Purification, characterization and molecular cloning of human hepatic lysosomal acid lipase. Eur. J. Biochem. 219, 905-914. doi: 10.1111/j.1432-1033.1994.tb18572.x

Anderson, R. A., Rao, N., Byrum, R. S., Rothschild, C. B., Bowden, D. W., Hayworth, R., et al. (1993). In situ localization of the genetic locus encoding the lysosomal acid lipase/cholesteryl esterase (LIPA) deficient in Wolman disease to chromosome 10q23.2-q23.3. Genomics 15, 245-247. doi: 10.1006/geno.1993.1052

Aviram, M. (1993). Modified forms of low density lipoprotein and atherosclerosis. Atherosclerosis 98, 1-9. doi: 10.1016/0021-9150(93)90217-I

Balwani, M., Breen, C., Enns, G. M., Deegan, P. B., Honzik, T., Jones, S., et al. (2013). Clinical effect and safety profile of recombinant human lysosomal acid lipase in patients with cholesteryl ester storage disease. Hepatology 58, 950-957. doi: 10.1002/hep.26289

Bernstein, D. L., Hulkova, H., Bialer, M. G., and Desnick, R. J. (2013). Cholesteryl ester storage disease: review of the findings in 135 reported patients with an underdiagnosed disease. J. Hepatol. 58, 1230-1243. doi: 10.1016/j.jhep.2013.02.014

Bhakdi, S., Dorweiler, B., Kirchmann, R., Torzewski, J., Weise, E., Tranum-Jensen, J., et al. (1995). On the pathogenesis of atherosclerosis: enzymatic transformation of human low density lipoprotein to an atherogenic moiety. J. Exp. Med. 182, 1959-1971. doi: 10.1084/jem.182.6.1959

Boadu, E., Choi, H. Y., Lee, D. W., Waddington, E. I., Chan, T., Asztalos, B., et al. (2006). Correction of apolipoprotein A-I-mediated lipid efflux and high density lipoprotein particle formation in human Niemann-Pick type C disease fibroblasts. J. Biol. Chem. 281, 37081-37090. doi: 10.1074/jbc.M6068 90200

Bowden, K. L., Bilbey, N. J., Bilawchuk, L. M., Boadu, E., Sidhu, R., Ory, D. S., et al. (2011). Lysosomal acid lipase deficiency impairs regulation of ABCA1 gene and formation of high density lipoproteins in cholesteryl ester storage disease. J. Biol. Chem. 286, 30624-30635. doi: 10.1074/jbc.M111.274381

Brecher, P., Pyun, H. Y., and Chobanian, A. V. (1977). Effect of atherosclerosis on lysosomal cholesterol esterase activity in rabbit aorta. J. Lipid Res. 18, 154-163.

Brown, A. J., and Jessup, W. (1999). Oxysterols and atherosclerosis. Atherosclerosis 142, 1-28. doi: 10.1016/S0021-9150(98)00196-8

Brown, A. J., Mander, E. L., Gelissen, I. C., Kritharides, L., Dean, R. T., and Jessup, W. (2000). Cholesterol and oxysterol metabolism and subcellular distribution in macrophage foam cells. Accumulation of oxidized esters in lysosomes. J. Lipid Res. 41, 226-237.

Brown, M. S., Dana, S. E., and Goldstein, J. L. (1975). Receptor-dependent hydrolysis of cholesteryl esters contained in plasma low density lipoprotein. Proc. Natl. Acad. Sci. U.S.A. 72, 2925-2929. doi: 10.1073/pnas.72.8.2925

Brown, M. S., and Goldstein, J. L. (1983). Lipoprotein metabolism in the macrophage: implications for cholesterol deposition in atherosclerosis. Annu. Rev. Biochem. 52, 223-261. doi: 10.1146/annurev.bi.52.070183.001255

Brown, M. S., and Goldstein, J. L. (1997). The SREBP pathway: regulation of cholesterol metabolism by proteolysis of a membrane-bound transcription factor. Cell 89, 331-340. doi: 10.1016/S0092-8674(00)80213-5

Brown, M. S., Goldstein, J. L., Krieger, M., Ho, Y. K., and Anderson, R. G. (1979). Reversible accumulation of cholesteryl esters in macrophages incubated with acetylated lipoproteins. J. Cell Biol. 82, 597-613. doi: 10.1083/jcb. 82.3.597

Burton, B. K., Emery, D., and Mueller, H. W. (1980). Lysosomal acid lipase in cultivated fibroblasts: characterization of enzyme activity in normal and enzymatically deficient cell lines. Clin. Chim. Acta 101, 25-32. doi: 10.1016/00098981(80)90052-2

Buton, X., Mamdouh, Z., Ghosh, R., Du, H., Kuriakose, G., Beatini, N., et al. (1999). Unique cellular events occurring during the initial interaction of macrophages with matrix-retained or methylated aggregated low density lipoprotein (LDL). Prolonged cell-surface contact during which ldl-cholesteryl ester hydrolysis exceeds ldl protein degradation. J. Biol. Chem. 274, 32112-32121. doi: 10.1074/jbc.274.45.32112

Chinetti-Gbaguidi, G., Rigamonti, E., Helin, L., Mutka, A. L., Lepore, M., Fruchart, J. C., et al. (2005). Peroxisome proliferator-activated receptor alpha controls cellular cholesterol trafficking in macrophages. J. Lipid Res. 46, 2717-2725. doi: 10.1194/jlr.M500326-JLR200

Chisolm, G. M., and Steinberg, D. (2000). The oxidative modification hypothesis of atherogenesis: an overview. Free Radic. Biol. Med. 28, 1815-1826. doi: 10.1016/S0891-5849(00)00344-0

Choi, H. Y., Karten, B., Chan, T., Vance, J. E., Greer, W. L., Heidenreich, R. A., et al. (2003). Impaired ABCA1-dependent lipid efflux and hypoalphalipoproteinemia in human Niemann-Pick type C disease. J. Biol. Chem. 278, 32569-32577. doi: 10.1074/jbc.M304553200

Choi, H. Y., Rahmani, M., Wong, B. W., Allahverdian, S., Mcmanus, B. M., Pickering, J. G., et al. (2009). ATP-binding cassette transporter Al expression and apolipoprotein A-I binding are impaired in intimatype arterial smooth muscle cells. Circulation 119, 3223-3231. doi: 10.1161/CIRCULATIONAHA.108.841130

Coltoff-Schiller, B., Goldfischer, S., Wolinsky, H., and Factor, S. M. (1976). Lipid accumulation in human aortic smooth muscle cell lysosomes. Am. J. Pathol. 83, $39-44$. 
Consortium, I. K. C. (2011). Large-scale gene-centric analysis identifies novel variants for coronary artery disease. PLoS Genet. 7:e1002260. doi: 10.1371/journal.pgen. 1002260

Coronary Artery Disease Genetics, C. (2011). A genome-wide association study in Europeans and South Asians identifies five new loci for coronary artery disease. Nat. Genet. 43, 339-344. doi: 10.1038/ng.782

Cox, B. E., Griffin, E. E., Ullery, J. C., and Jerome, W. G. (2007). Effects of cellular cholesterol loading on macrophage foam cell lysosome acidification. J. Lipid Res. 48, 1012-1021. doi: 10.1194/jlr.M600390-JLR200

Davis, H. R., Glagov, S., and Zarins, C. K. (1985). Role of acid lipase in cholesteryl ester accumulation during atherogenesis. Correlation of enzyme activity with acid lipase-containing macrophages in rabbit and human lesions. Atherosclerosis 55, 205-215. doi: 10.1016/0021-9150(85)90099-1

De Duve, C. (1974). The participation of lysosomes in the transformation of smooth muscle cells to foamy cells in the aorta of cholesterol-fed rabbits. Acta Cardiol. Suppl. 20, 9-25.

Dhaliwal, B. S., and Steinbrecher, U. P. (2000). Cholesterol delivered to macrophages by oxidized low density lipoprotein is sequestered in lysosomes and fails to efflux normally. J. Lipid Res. 41, 1658-1665.

Doran, A. C., Meller, N., and Mcnamara, C. A. (2008). Role of smooth muscle cells in the initiation and early progression of atherosclerosis. Arterioscler. Thromb. Vasc. Biol. 28, 812-819. doi: 10.1161/ATVBAHA.107.159327

Du, H., Schiavi, S., Levine, M., Mishra, J., Heur, M., and Grabowski, G. A. (2001). Enzyme therapy for lysosomal acid lipase deficiency in the mouse. Hum. Mol. Genet. 10, 1639-1648. doi: 10.1093/hmg/10.16.1639

Du, H., Schiavi, S., Wan, N., Levine, M., Witte, D. P., and Grabowski, G. A. (2004). Reduction of atherosclerotic plaques by lysosomal acid lipase supplementation. Arterioscler. Thromb. Vasc. Biol. 24, 147-154. doi: 10.1161/01.ATV.0000107030.22053.1e

Efeyan, A., Zoncu, R., and Sabatini, D. M. (2012). Amino acids and mTORC1: from lysosomes to disease. Trends Mol. Med. 18, 524-533. doi: 10.1016/j.molmed.2012.05.007

Emanuel, R., Sergin, I., Bhattacharya, S., Turner, J. N., Epelman, S., Settembre, C., et al. (2014). Induction of lysosomal biogenesis in atherosclerotic macrophages can rescue lipid-induced lysosomal dysfunction and downstream sequelae. Arterioscler. Thromb. Vasc. Biol. 34, 1942-1952. doi: 10.1161/ATVBAHA.114.303342

Falcone, D. J., and Salisbury, B. G. (1988). Fibronectin stimulates macrophage uptake of low density lipoprotein-heparin-collagen complexes. Arteriosclerosis 8, 263-273. doi: 10.1161/01.ATV.8.3.263

Fowler, S., Berberian, P. A., Shio, H., Goldfischer, S., and Wolinsky, H. (1980). Characterization of cell populations isolated from aortas of rhesus monkeys with experimental atherosclerosis. Circ Res 46, 520-530. doi: 10.1161/01.RES.46.4.520

Garver, W. S., Jelinek, D., Francis, G. A., and Murphy, B. D. (2008). The NiemannPick $\mathrm{C} 1$ gene is downregulated by feedback inhibition of the SREBP pathway in human fibroblasts. J. Lipid Res. 49, 1090-1102. doi: 10.1194/jlr.M700555JLR200

Garver, W. S., Jelinek, D., Meaney, F. J., Flynn, J., Pettit, K. M., Shepherd, G., et al. (2010). The National Niemann-Pick Type C1 Disease Database: correlation of lipid profiles, mutations, and biochemical phenotypes. J. Lipid Res. 51, 406-415. doi: 10.1194/jlr.P000331

Gaut, J. P., and Heinecke, J. W. (2001). Mechanisms for oxidizing low-density lipoprotein. Insights from patterns of oxidation products in the artery wall and from mouse models of atherosclerosis. Trends Cardiovasc. Med. 11, 103-112. doi: 10.1016/S1050-1738(01)00101-3

Goldfischer, S., Schiller, B., and Wolinsky, H. (1975). Lipid accumulation in smooth muscle cell lysosomes im primate atherosclerosis. Am. J. Pathol. 78, 497-504.

Goldstein, J. L., and Brown, M. S. (1977). The low-density lipoprotein pathway and its relation to atherosclerosis. Annu. Rev. Biochem. 46, 897-930. doi: 10.1146/annurev.bi.46.070177.004341

Goldstein, J. L., and Brown, M. S. (2009). The LDL receptor. Arterioscler. Thromb. Vasc. Biol. 29, 431-438. doi: 10.1161/ATVBAHA.108.179564

Goldstein, J. L., Dana, S. E., Faust, J. R., Beaudet, A. L., and Brown, M. S. (1975). Role of lysosomal acid lipase in the metabolism of plasma low density lipoprotein. Observations in cultured fibroblasts from a patient with cholesteryl ester storage disease. J. Biol. Chem. 250, 8487-8495.

Goldstein, J. L., Hoff, H. F., Ho, Y. K., Basu, S. K., and Brown, M. S. (1981). Stimulation of cholesteryl ester synthesis in macrophages by extracts of atherosclerotic human aortas and complexes of albumin/cholesteryl esters. Arteriosclerosis 1, 210-226. doi: 10.1161/01.ATV.1.3.210

Grabowski, G. A., Du, H., and Charnas, L. (2014). "Lysosomal acid lipase deficiencies: the wolman disease/cholesteryl ester storage disease spectrum," in The Online Metabolic and Molecular Bases of Inherited Disease, eds A. L. Beaudet, B. Vogelstein, K. W. Kinzler, S. E. Antonarakis, A. Ballabio, K. M. Gibson, et al. (New York, NY: The McGraw-Hill Companies, Inc.).

Griffin, E. E., Ullery, J. C., Cox, B. E., and Jerome, W. G. (2005). Aggregated LDL and lipid dispersions induce lysosomal cholesteryl ester accumulation in macrophage foam cells. J. Lipid Res. 46, 2052-2060. doi: 10.1194/jlr.M500059JLR200

Guyton, J. R., and Klemp, K. F. (1993). Transitional features in human atherosclerosis. Intimal thickening, cholesterol clefts, and cell loss in human aortic fatty streaks. Am. J. Pathol. 143, 1444-1457.

Hakala, J. K., Oksjoki, R., Laine, P., Du, H., Grabowski, G. A., Kovanen, P. T., et al. (2003). Lysosomal enzymes are released from cultured human macrophages, hydrolyze LDL in vitro, and are present extracellularly in human atherosclerotic lesions. Arterioscler. Thromb. Vasc. Biol. 23, 1430-1436. doi: 10.1161/01.ATV.0000077207.49221.06

Haley, N. J., Fowler, S., and De Duve, C. (1980). Lysosomal acid cholesteryl esterase activity in normal and lipid-laden aortic cells. J. Lipid Res. 21, 961-969.

Haust, M. D. (1971). The morphogenesis and fate of potential and early atherosclerotic lesions in man. Hum. Pathol. 2, 1-29. doi: 10.1016/S0046-8177(71)80019-9

He, C., and Klionsky, D. J. (2009). Regulation mechanisms and signaling pathways of autophagy. Annu. Rev. Genet. 43, 67-93. doi: 10.1146/annurev-genet-102808114910

Heltianu, C., Robciuc, A., Botez, G., Musina, C., Stancu, C., Sima, A. V., et al. (2011). Modified low density lipoproteins decrease the activity and expression of lysosomal acid lipase in human endothelial and smooth muscle cells. Cell Biochem. Biophys. 61, 209-216. doi: 10.1007/s12013-011-9190-8

Hoff, H. F., and Hoppe, G. (1995). Structure of cholesterol-containing particles accumulating in atherosclerotic lesions and the mechanisms of their derivation. Curr. Opin. Lipidol. 6, 317-325. doi: 10.1097/00041433-199510000-00012

Hoff, H. F., and Morton, R. E. (1985). Lipoproteins containing apo B extracted from human aortas. Structure and function. Ann. N.Y. Acad. Sci. 454, 183-194. doi: 10.1111/j.1749-6632.1985.tb11857.x

Hoff, H. F., O'neil, J., Pepin, J. M., and Cole, T. B. (1990). Macrophage uptake of cholesterol-containing particles derived from LDL and isolated from atherosclerotic lesions. Eur. Heart J. 11(Suppl. E), 105-115. doi: 10.1093/eurheartj/11.suppl_E.105

Hoppe, G., O'neil, J., and Hoff, H. F. (1994). Inactivation of lysosomal proteases by oxidized low density lipoprotein is partially responsible for its poor degradation by mouse peritoneal macrophages. J. Clin. Invest. 94, 1506-1512. doi: 10.1172/JCI117490

Itabe, H., Suzuki, K., Tsukamoto, Y., Komatsu, R., Ueda, M., Mori, M., et al. (2000). Lysosomal accumulation of oxidized phosphatidylcholine-apolipoprotein B complex in macrophages: intracellular fate of oxidized low density lipoprotein. Biochim. Biophys. Acta 1487, 233-245. doi: 10.1016/S1388-1981(00)00098-6

Jelinek, D., Castillo, J. J., Richardson, L. M., Luo, L., Heidenreich, R. A., and Garver, W. S. (2012). The Niemann-Pick C1 gene is downregulated in livers of C57BL/6 mice by dietary fatty acids, but not dietary cholesterol, through feedback inhibition of the SREBP pathway. J. Nutr. 142, 1935-1942. doi: 10.3945/jn.112.162818

Jelinek, D., Patrick, S. M., Kitt, K. N., Chan, T., Francis, G. A., and Garver, W. S. (2009). Physiological and coordinate downregulation of the NPC1 and NPC2 genes are associated with the sequestration of LDL-derived cholesterol within endocytic compartments. J. Cell Biochem. 108, 1102-1116. doi: $10.1002 /$ jcb. 22339

Jerome, W. G. (2006). Advanced atherosclerotic foam cell formation has features of an acquired lysosomal storage disorder. Rejuvenation Res. 9, 245-255. doi: 10.1089/rej.2006.9.245

Jerome, W. G., Cox, B. E., Griffin, E. E., and Ullery, J. C. (2008). Lysosomal cholesterol accumulation inhibits subsequent hydrolysis of lipoprotein cholesteryl ester. Microsc. Microanal. 14, 138-149. doi: 10.1017/S1431927608080069

Jerome, W. G., and Lewis, J. C. (1985). Early atherogenesis in White Carneau pigeons. II. Ultrastructural and cytochemical observations. Am. J. Pathol. 119, 210-222.

Jerome, W. G., and Yancey, P. G. (2003). The role of microscopy in understanding atherosclerotic lysosomal lipid metabolism. Microsc. Microanal. 9, 54-67. doi: $10.1017 /$ S1431927603030010 
Jerome, W. G. C., Cox, B., and Vaughan, J. B. (2002). The distribution of NPC-1 protein in macrophages is altered after oxidized LDL lyososomal accumulation. Microsc Microanal 8, 894-895.

Jessup, W., and Kritharides, L. (2000). Metabolism of oxidized LDL by macrophages. Curr. Opin. Lipidol. 11, 473-481. doi: 10.1097/00041433200010000-00005

Jessup, W., Mander, E. L., and Dean, R. T. (1992). The intracellular storage and turnover of apolipoprotein B of oxidized LDL in macrophages. Biochim. Biophys. Acta 1126, 167-177. doi: 10.1016/0005-2760(92)90287-6

Kruth, H. S. (2002). Sequestration of aggregated low-density lipoproteins by macrophages. Curr. Opin. Lipidol. 13, 483-488. doi: 10.1097/00041433200210000-00003

Kwon, H. J., Abi-Mosleh, L., Wang, M. L., Deisenhofer, J., Goldstein, J. L., Brown, M. S., et al. (2009). Structure of N-terminal domain of NPC1 reveals distinct subdomains for binding and transfer of cholesterol. Cell 137, 1213-1224. doi: 10.1016/j.cell.2009.03.049

Lake, B. D., and Patrick, A. D. (1970). Wolman's disease: deficiency of E600resistant acid esterase activity with storage of lipids in lysosomes. J. Pediatr. 76, 262-266. doi: 10.1016/S0022-3476(70)80172-X

Lettieri Barbato, D., Tatulli, G., Aquilano, K., and Ciriolo, M. R. (2013). FoxO1 controls lysosomal acid lipase in adipocytes: implication of lipophagy during nutrient restriction and metformin treatment. Cell Death Dis. 4, e861. doi: 10.1038/cddis.2013.404

Li, H., Freeman, M. W., and Libby, P. (1995). Regulation of smooth muscle cell scavenger receptor expression in vivo by atherogenic diets and in vitro by cytokines. J. Clin. Invest. 95, 122-133. doi: 10.1172/JCI117628

Li, W., Yuan, X. M., Olsson, A. G., and Brunk, U. T. (1998). Uptake of oxidized LDL by macrophages results in partial lysosomal enzyme inactivation and relocation. Arterioscler. Thromb. Vasc. Biol. 18, 177-184. doi: 10.1161/01.ATV. 18.2.177

Liscum, L., and Faust, J. R. (1987). Low density lipoprotein (LDL)-mediated suppression of cholesterol synthesis and LDL uptake is defective in Niemann-Pick type C fibroblasts. J. Biol. Chem. 262, 17002-17008.

Lougheed, M., Zhang, H. F., and Steinbrecher, U. P. (1991). Oxidized low density lipoprotein is resistant to cathepsins and accumulates within macrophages. J. Biol. Chem. 266, 14519-14525.

Mander, E. L., Dean, R. T., Stanley, K. K., and Jessup, W. (1994). Apolipoprotein $\mathrm{B}$ of oxidized LDL accumulates in the lysosomes of macrophages. Biochim. Biophys. Acta 1212, 80-92. doi: 10.1016/0005-2760(94)90192-9

Maor, I., and Aviram, M. (1994). Oxidized low density lipoprotein leads to macrophage accumulation of unesterified cholesterol as a result of lysosomal trapping of the lipoprotein hydrolyzed cholesteryl ester. J. Lipid Res. 35 , 803-819.

Maor, I., and Aviram, M. (1999). Macrophage released proteoglycans are involved in cell-mediated aggregation of LDL. Atherosclerosis 142, 57-66. doi: 10.1016/S0021-9150(98)00191-9

Mehrabi, M. R., Sinzinger, H., Ekmekcioglu, C., Tamaddon, F., Plesch, K., Glogar, H. D., et al. (2000). Accumulation of oxidized LDL in human semilunar valves correlates with coronary atherosclerosis. Cardiovasc. Res. 45, 874-882. doi: 10.1016/S0008-6363(99)00389-2

Miller, B. F., and Kothari, H. V. (1969). Increased activity of lysosomal enzymes in human atherosclerotic aortas. Exp Mol Pathol 10, 288-294. doi: 10.1016/00144800(69)90058-6

Moore, K. J., and Freeman, M. W. (2006). Scavenger receptors in atherosclerosis: beyond lipid uptake. Arterioscler. Thromb. Vasc. Biol. 26, 1702-1711. doi 10.1161/01.ATV.0000229218.97976.43

Naghavi, M., John, R., Naguib, S., Siadaty, M. S., Grasu, R., Kurian, K. C., et al. (2002). pH Heterogeneity of human and rabbit atherosclerotic plaques; a new insight into detection of vulnerable plaque. Atherosclerosis 164, 27-35. doi: 10.1016/S0021-9150(02)00018-7

Newsholme, P., Gordon, S., and Newsholme, E. A. (1987). Rates of utilization and fates of glucose, glutamine, pyruvate, fatty acids and ketone bodies by mouse macrophages. Biochem. J. 242, 631-636.

Niu, X., Zammit, V., Upston, J. M., Dean, R. T., and Stocker, R. (1999). Coexistence of oxidized lipids and alpha-tocopherol in all lipoprotein density fractions isolated from advanced human atherosclerotic plaques. Arterioscler. Thromb. Vasc. Biol. 19, 1708-1718. doi: 10.1161/01.ATV.19.7.1708

O'neil, J., Hoppe, G., and Hoff, H. F. (2003). Phospholipids in oxidized low density lipoproteins perturb the ability of macrophages to degrade internalized macromolecules and reduce intracellular cathepsin B activity. Atherosclerosis 169, 215-224. doi: 10.1016/S0021-9150(03)00104-7

Oram, J. F., and Heinecke, J. W. (2005). ATP-binding cassette transporter A1: a cell cholesterol exporter that protects against cardiovascular disease. Physiol. Rev. 85, 1343-1372. doi: 10.1152/physrev.00005.2005

Orso, E., Grandl, M., and Schmitz, G. (2011). Oxidized LDL-induced endolysosomal phospholipidosis and enzymatically modified LDL-induced foam cell formation determine specific lipid species modulation in human macrophages. Chem. Phys. Lipids 164, 479-487. doi: 10.1016/j.chemphyslip.2011.06.001

Ouimet, M., Franklin, V., Mak, E., Liao, X., Tabas, I., and Marcel, Y. L. (2011). Autophagy regulates cholesterol efflux from macrophage foam cells via lysosomal acid lipase. Cell Metab. 13, 655-667. doi: 10.1016/j.cmet.2011.03.023

Parthasarathy, S., Raghavamenon, A., Garelnabi, M. O., and Santanam, N. (2010). Oxidized low-density lipoprotein. Methods Mol. Biol. 610, 403-417. doi: 10.1007/978-1-60327-029-8_24

Patrick, A. D., and Lake, B. D. (1969). Deficiency of an acid lipase in Wolman's disease. Nature 222, 1067-1068. doi: 10.1038/2221067a0

Peters, T. J., and De Duve, C. (1974). Lysosomes of the arterial wall. II. Subcellular fractionation of aortic cells from rabbits with experimantal atheroma. Exp. Mol. Pathol. 20, 228-256. doi: 10.1016/0014-4800(74)90057-4

Peters, T. J., Muller, M., and De Duve, C. (1972). Lysosomes of the arterial wall. I. Isolation and subcellular fractionation of cells from normal rabbit aorta. J. Exp. Med. 136, 1117-1139. doi: 10.1084/jem.136.5.1117

Ries, S., Buchler, C., Langmann, T., Fehringer, P., Aslanidis, C., and Schmitz, G. (1998). Transcriptional regulation of lysosomal acid lipase in differentiating monocytes is mediated by transcription factors Sp1 and AP-2. J. Lipid Res. 39, 2125-2134.

Rigamonti, E., Helin, L., Lestavel, S., Mutka, A. L., Lepore, M., Fontaine, C., et al. (2005). Liver X receptor activation controls intracellular cholesterol trafficking and esterification in human macrophages. Circ. Res. 97, 682-689. doi: 10.1161/01.RES.0000184678.43488.9f

Roma, P., Bernini, F., Fogliatto, R., Bertulli, S. M., Negri, S., Fumagalli, R., et al. (1992). Defective catabolism of oxidized LDL by J774 murine macrophages. J. Lipid Res. 33, 819-829.

Sando, G. N., and Henke, V. L. (1982). Recognition and receptor-mediated endocytosis of the lysosomal acid lipase secreted by cultured human fibroblasts. J. Lipid Res. 23, 114-123.

Sandri, M. (2012). FOXOphagy path to inducing stress resistance and cell survival. Nat. Cell Biol. 14, 786-788. doi: 10.1038/ncb2550

Sardiello, M., Palmieri, M., Di Ronza, A., Medina, D. L., Valenza, M., Gennarino, V. A., et al. (2009). A gene network regulating lysosomal biogenesis and function. Science 325, 473-477. doi: 10.1126/science.1174447

Schnyder, J., and Baggiolini, M. (1978). Secretion of lysosomal hydrolases by stimulated and nonstimulated macrophages. J. Exp. Med. 148, 435-450. doi: 10.1084/jem.148.2.435

Scott, S. A., Liu, B., Nazarenko, I., Martis, S., Kozlitina, J., Yang, Y., et al. (2013). Frequency of the cholesteryl ester storage disease common LIPA E8SJM mutation (c.894G $>\mathrm{A})$ in various racial and ethnic groups. Hepatology 58, 958-965. doi: $10.1002 /$ hep. 26327

Sergin, I., and Razani, B. (2014). Self-eating in the plaque: what macrophage autophagy reveals about atherosclerosis. Trends Endocrinol. Metab. 25, 225-234. doi: 10.1016/j.tem.2014.03.010

Settembre, C., De Cegli, R., Mansueto, G., Saha, P. K., Vetrini, F., Visvikis, O., et al. (2013). TFEB controls cellular lipid metabolism through a starvationinduced autoregulatory loop. Nat. Cell Biol. 15, 647-658. doi: 10.1038/ ncb2718

Settembre, C., Zoncu, R., Medina, D. L., Vetrini, F., Erdin, S., Erdin, S., et al. (2012). A lysosome-to-nucleus signalling mechanism senses and regulates the lysosome via mTOR and TFEB. EMBO J. 31, 1095-1108. doi: 10.1038/emboj. 2012.32

Shanware, N. P., Bray, K., and Abraham, R. T. (2013). The PI3K, metabolic, and autophagy networks: interactive partners in cellular health and disease. Annu. Rev. Pharmacol. Toxicol. 53, 89-106. doi: 10.1146/annurev-pharmtox-010611134717

Sheriff, S., Du, H., and Grabowski, G. A. (1995). Characterization of lysosomal acid lipase by site-directed mutagenesis and heterologous expression. J. Biol. Chem. 270, 27766-27772. doi: 10.1074/jbc.270.46.27766

Shio, H., Farquhar, M. G., and De Duve, C. (1974). Lysosomes of the arterial wall. IV. Cytochemical localization of acid phosphatase and catalase in smooth 
muscle cells and foam cells from rabbit atheromatous aorta. Am. J. Pathol. 76, 1-16.

Shio, H., Haley, N. J., and Fowler, S. (1979). Characterization of lipid-laden aortic cells from cholesterol-fed rabbits. III. Intracellular localization of cholesterol and cholesteryl ester. Lab. Invest. 41, 160-167.

Singh, R., Kaushik, S., Wang, Y., Xiang, Y., Novak, I., Komatsu, M., et al. (2009). Autophagy regulates lipid metabolism. Nature 458, 1131-1135. doi: 10.1038 /nature07976

Sloan, H. R., and Fredrickson, D. S. (1972). Enzyme deficiency in cholesteryl ester storage idisease. J. Clin. Invest. 51, 1923-1926. doi: 10.1172/JCI106997

Steinberg, D., and Witztum, J. L. (2002). Is the oxidative modification hypothesis relevant to human atherosclerosis? Do the antioxidant trials conducted to date refute the hypothesis? Circulation 105, 2107-2111. doi: 10.1161/01.CIR.0000014762.06201.06

Steinbrecher, U. P., and Lougheed, M. (1992). Scavenger receptor-independent stimulation of cholesterol esterification in macrophages by low density lipoprotein extracted from human aortic intima. Arterioscler. Thromb. 12, 608-625. doi: 10.1161/01.ATV.12.5.608

Stitziel, N. O., Fouchier, S. W., Sjouke, B., Peloso, G. M., Moscoso, A. M., Auer, P. L., et al. (2013). Exome sequencing and directed clinical phenotyping diagnose cholesterol ester storage disease presenting as autosomal recessive hypercholesterolemia. Arterioscler. Thromb. Vasc. Biol. 33, 2909-2914. doi: 10.1161/ATVBAHA.113.302426

Stocker, R., and Keaney, J. F. Jr. (2004). Role of oxidative modifications in atherosclerosis. Physiol. Rev. 84, 1381-1478. doi: 10.1152/physrev.00047.2003

Subbiah, M. T. (1979). Significance of various cholesterol, ester hydrolases in aorta. Steroids 33, 305-315. doi: 10.1016/0039-128X(79)90007-2

Suits, A. G., Chait, A., Aviram, M., and Heinecke, J. W. (1989). Phagocytosis of aggregated lipoprotein by macrophages: low density lipoprotein receptordependent foam-cell formation. Proc. Natl. Acad. Sci. U.S.A. 86, 2713-2717. doi: 10.1073/pnas.86.8.2713

Sun, Y., Xu, Y. H., Du, H., Quinn, B., Liou, B., Stanton, L., et al. (2014). Reversal of advanced disease in lysosomal acid lipase deficient mice: a model for lysosomal acid lipase deficiency disease. Mol. Genet. Metab. 112, 229-241. doi: 10.1016/j.ymgme.2014.04.006

Tabas, I. (2002). Consequences of cellular cholesterol accumulation: basic concepts and physiological implications. J. Clin. Invest. 110, 905-911. doi: 10.1172/JCI0216452

Tabas, I., Williams, K. J., and Boren, J. (2007). Subendothelial lipoprotein retention as the initiating process in atherosclerosis: update and therapeutic implications. Circulation 116, 1832-1844. doi: 10.1161/CIRCULATIONAHA.106.676890

Takano, T., Black, W. J., Peters, T. J., and De Duve, C. (1974). Assay, kinetics, and lysosomal localization of an acid cholesteryl esterase in rabbit aortic smooth muscle cells. J. Biol. Chem. 249, 6732-6737.

Takano, T. I., T. (1978). Lysosomal acid cholesteryl esterase and atherosclerosis in cholesterol-fed rabbits. Acta Histochem. Cytochem. 11, 323-336. doi: 10.1267/ahc. 11.323

Tangirala, R. K., Jerome, W. G., Jones, N. L., Small, D. M., Johnson, W. J., Glick, J. M., et al. (1994). Formation of cholesterol monohydrate crystals in macrophage-derived foam cells. J. Lipid Res. 35, 93-104.

Tapper, H., and Sundler, R. (1990). Role of lysosomal and cytosolic pH in the regulation of macrophage lysosomal enzyme secretion. Biochem. J. 272, 407-414.

Tapper, H., and Sundler, R. (1992). Cytosolic pH regulation in mouse macrophages. Proton extrusion by plasma-membrane-localized $\mathrm{H}(+)$-ATPase. Biochem. J. 281(Pt 1), 245-250.

Tertov, V. V., Orekhov, A. N., Sobenin, I. A., Gabbasov, Z. A., Popov, E. G., Yaroslavov, A. A., et al. (1992). Three types of naturally occurring modified lipoproteins induce intracellular lipid accumulation due to lipoprotein aggregation. Circ. Res. 71, 218-228. doi: 10.1161/01.RES.71.1.218

Torzewski, M., Klouche, M., Hock, J., Messner, M., Dorweiler, B., Torzewski, J., et al. (1998). Immunohistochemical demonstration of enzymatically modified human LDL and its colocalization with the terminal complement complex in the early atherosclerotic lesion. Arterioscler. Thromb. Vasc. Biol. 18, 369-378. doi: 10.1161/01.ATV.18.3.369
Torzewski, M., and Lackner, K. J. (2006). Initiation and progression of atherosclerosis-enzymatic or oxidative modification of low-density lipoprotein? Clin. Chem. Lab. Med. 44, 1389-1394. doi: 10.1515/CCLM.2006.259

Ullery-Ricewick, J. C., Cox, B. E., Griffin, E. E., and Jerome, W. G. (2009). Triglyceride alters lysosomal cholesterol ester metabolism in cholesteryl ester-laden macrophage foam cells. J. Lipid Res. 50, 2014-2026. doi: 10.1194/jlr.M800659-JLR200

Venkateswaran, A., Laffitte, B. A., Joseph, S. B., Mak, P. A., Wilpitz, D. C., Edwards, P. A., et al. (2000). Control of cellular cholesterol efflux by the nuclear oxysterol receptor LXR alpha. Proc. Natl. Acad. Sci. U.S.A. 97, 12097-12102. doi: 10.1073/pnas.200367697

Wen, Y., and Leake, D. S. (2007). Low density lipoprotein undergoes oxidation within lysosomes in cells. Circ. Res. 100, 1337-1343. doi: 10.1161/CIRCRESAHA.107.151704

Wild, P. S., Zeller, T., Schillert, A., Szymczak, S., Sinning, C. R., Deiseroth, A. et al. (2011). A genome-wide association study identifies LIPA as a susceptibility gene for coronary artery disease. Circ. Cardiovasc. Genet. 4, 403-412. doi: 10.1161/CIRCGENETICS.110.958728

Williams, K. J., and Tabas, I. (1995). The response-to-retention hypothesis of early atherogenesis. Arterioscler. Thromb. Vasc. Biol. 15, 551-561. doi: 10.1161/01.ATV.15.5.551

Williams, K. J., and Tabas, I. (2005). Lipoprotein retention-and clues for atheroma regression. Arterioscler. Thromb. Vasc. Biol. 25, 1536-1540. doi: 10.1161/01.ATV.0000174795.62387.d3

$\mathrm{Xu}, \mathrm{S}$., and Lin, B. (2001). The mechanism of oxidation-induced low-density lipoprotein aggregation: an analogy to colloidal aggregation and beyond? Biophys. J. 81, 2403-2413. doi: 10.1016/S0006-3495(01)75887-0

Xu, X. X., and Tabas, I. (1991). Sphingomyelinase enhances low density lipoprotein uptake and ability to induce cholesteryl ester accumulation in macrophages. J. Biol. Chem. 266, 24849-24858.

Yancey, P. G., and Jerome, W. G. (1998). Lysosomal sequestration of free and esterified cholesterol from oxidized low density lipoprotein in macrophages of different species. J. Lipid Res. 39, 1349-1361.

Yancey, P. G., and Jerome, W. G. (2001). Lysosomal cholesterol derived from mildly oxidized low density lipoprotein is resistant to efflux. J. Lipid Res. 42, 317-327.

Yoshida, H., and Kisugi, R. (2010). Mechanisms of LDL oxidation. Clin. Chim. Acta 411, 1875-1882. doi: 10.1016/j.cca.2010.08.038

Yu, X., Li, X., Zhao, G., Xiao, J., Mo, Z., Yin, K., et al. (2012). OxLDL up-regulates Niemann-Pick type $\mathrm{Cl}$ expression through ERK1/2/COX2/PPARalpha-signaling pathway in macrophages. Acta Biochim. Biophys. Sin. (Shanghai) 44, 119-128. doi: 10.1093/abbs/gmr119

Yuan, X. M., Li, W., Brunk, U. T., Dalen, H., Chang, Y. H., and Sevanian, A. (2000). Lysosomal destabilization during macrophage damage induced by cholesterol oxidation products. Free Radic. Biol. Med. 28, 208-218. doi: 10.1016/S08915849(99)00220-8

Conflict of Interest Statement: The authors declare that the research was conducted in the absence of any commercial or financial relationships that could be construed as a potential conflict of interest.

Received: 23 October 2014; accepted: 07 January 2015; published online: 02 February 2015.

Citation: Dubland JA and Francis GA (2015) Lysosomal acid lipase: at the crossroads of normal and atherogenic cholesterol metabolism. Front. Cell Dev. Biol. 3:3. doi: $10.3389 /$ fcell.2015.00003

This article was submitted to Lipidology, a section of the journal Frontiers in Cell and Developmental Biology.

Copyright (c) 2015 Dubland and Francis. This is an open-access article distributed under the terms of the Creative Commons Attribution License (CC BY). The use, distribution or reproduction in other forums is permitted, provided the original author(s) or licensor are credited and that the original publication in this journal is cited, in accordance with accepted academic practice. No use, distribution or reproduction is permitted which does not comply with these terms. 